\title{
Educação inclusiva: as implicações das traduções e das interpretações da Declaração de Salamanca no Brasil
}

\author{
Fabiane Vanessa Breitenbach a \\ Cláucia Honnef ${ }^{b}$ \\ Fabiane Adela Tonetto Costas ${ }^{c}$
}

\section{Resumo}

As mudanças na atual versão da Declaração de Salamanca e sua influência na elaboração de documentos legais confirmam que educação inclusiva e Educação Especial têm sido consideradas sinônimas em nosso país. Assim, este artigo problematiza o conceito de educação inclusiva difundido em políticas públicas e no contexto escolar brasileiro, a partir da primeira tradução da Declaração de Salamanca, disponível em 1994 e reeditada em 1997, e da segunda tradução, que hoje está disponível em meio digital no website do Ministério da Educação. A opção metodológica envolveu a pesquisa documental e a análise documental. A partir delas, buscamos constatar e analisar de que forma as alterações na Declaração de Salamanca, hoje publicizada e veiculada no Brasil, colocaram a educação inclusiva como tarefa da Educação Especial, provocando uma miscelânea de conceitos, definições e interpretações envolvendo essas duas expressões. Foi possível observar que as políticas públicas para a educação inclusiva e a Educação Especial foram/estão sendo propostas tendo por base as modificações e as interpretações dessa Declaração. As alterações aparentemente despretensiosas na Declaração de Salamanca e a miscelânea de conceitos e definições sobre as pessoas denominadas público-alvo da educação inclusiva e da Educação Especial podem ter causado confusões conceituais e, certamente, conduzido o rumo da história das políticas e pesquisas sobre essas temáticas no Brasil.

Palavras-chave: Educação inclusiva. Educação Especial. Declaração de Salamanca.

\footnotetext{
a UFSM, Núcleo de Acessibilidade. Santa Maria, Rio Grande do Sul, Brasil.

b UFSM, Unidade de Educação Infantil Ipê Amarelo. Santa Maria, Rio Grande do Sul, Brasil.

c Universidade Federal de Santa Maria - UFSM, Departamento de Fundamentos da Educação, Programa de Pós-Graduação em Educação - PPGE. Santa Maria, Rio Grande do Sul, Brasil.
} 


\section{Introdução}

No Brasil, com o advento da educação inclusiva, colocou-se em foco a Educação Especial e as pessoas que foram consideradas seu alunado ao longo do tempo. A partir disso, muitas pessoas passaram a se referir à educação inclusiva e à Educação Especial como conceitos sinônimos, compreendendo que a educação inclusiva nasceu para justificar a inserção dos alunos da Educação Especial nas classes de ensino regular. Na mídia, em trabalhos acadêmicos e nas políticas governamentais, têm-se discursos de promoção da educação inclusiva no cenário da Educação Especial, defendendo a inserção dos alunos figurados como público-alvo ${ }^{1}$ da Educação Especial em escolas comuns, passando essas escolas a serem denominadas de inclusivas.

Nessa perspectiva, no presente trabalho, buscamos problematizar os preceitos que têm se configurado como educação inclusiva no Brasil: Como a educação inclusiva e a Educação Especial são percebidas hoje nos espaços e nas políticas educacionais, e como estão pontuadas nos estudos acadêmicos? Educação inclusiva resume-se à escolarização das pessoas tidas como alunas da Educação Especial em escolas e classes comuns? Quem são as pessoas que devem ser contempladas pela educação inclusiva? Como uma escola inclusiva configura-se ou deve configurar-se? É possível falar/fazer educação inclusiva em uma sociedade como a nossa, com desigualdades econômicas e, consequentemente, educacionais consideráveis?

Acreditamos que pensar os processos de inclusão e de não segregação na escola contrapõe-se às crescentes desigualdades sociais e à segregação cada vez maior de parcelas significativas da sociedade, de forma que é permitido afirmar que "não se conseguirá alcançar uma educação verdadeiramente inclusiva numa sociedade excludente" (BUENO, 2008, p.55).

Bueno $^{2}(2006,2008)$ pontua que, no Brasil, o fracasso escolar é uma marca constitutiva do sistema escolar e que o processo de seletividade mudou a "roupagem", mas segue afetando os alunos das classes menos favorecidas, pois, se anteriormente a seletividade dava-se pelo não acesso, pelos elevados índices de evasão e pela repetência, atualmente, ela acontece através da baixa aprendizagem e da não aprendizagem.

\footnotetext{
Segundo a Política Nacional de Educação Especial na Perspectiva da Educação Inclusiva (BRASIL, 2008), considera-se público-alvo da Educação Especial os estudantes com deficiência, transtornos globais do desenvolvimento e altas habilidades/superdotação.

2 Para o autor, as políticas e as reformas educacionais, implantadas no país desde a Reforma Francisco Campos até as atuais políticas de inclusão escolar, tiveram como uma das justificativas a diminuição do fracasso da escola básica.
} 
Nas políticas públicas educacionais e na literatura sobre a temática da inclusão na educação, encontram-se diferentes expressões e definições, diferentes beneficiários e também muitas contradições. A polissemia relacionada à educação inclusiva justifica-se, de certa forma, pelo seu caráter de inacabamento ${ }^{3}$ e pela forma como constituíram-se as políticas de Educação Especial no Brasil.

Desse modo, em nossas pesquisas, identificamos que o estudo daquilo que se denomina educação inclusiva e os seus mais diferentes desdobramentos não é tarefa simples. Entretanto, é necessária uma análise dos significados que esse termo pode ter e trazer a nossa realidade educacional e, pensando nisso, apresentamos e discutimos algumas dessas significações, tendo por base a pesquisa e análise documental (CELLARD, 2008; FIGUEIREDO, 2007; LÜDKE; ANDRÉ, 1986) das versões da Declaração de Salamanca (1994), um dos documentos que influenciou a elaboração da Política Nacional de Educação Especial na Perspectiva da Educação Inclusiva (BRASIL, 2008). Para sustentar nossas análises, apoiamo-nos em publicações de pesquisadores da área da Educação Especial que se dedicaram com mais ênfase a investigar as políticas de inclusão no espaço de educação formal das pessoas que têm sido, historicamente, considerados como alunos da Educação Especial.

\section{Contextualização metodológica}

Para este estudo, utilizamos a pesquisa documental, que se constitui como metodologia exiguamente implementada na área da Educação e em outros campos das Ciências Sociais e Humanas. (LÜDKE; ANDRÉ, 1986). O uso de documentos como manancial de pesquisa é deveras importante, pois a quantidade de subsídios advindos dessas fontes valida sua consideração nas Ciências Humanas e Sociais, porquanto, permite a compreensão de elementos cuja abrangência precisa de dados que envolvam o contexto histórico e sociocultural. Documentos escritos compõem um manancial bastante valioso para quem pesquisa nas Ciências Sociais e Humanas, pois, por meio dessas fontes, torna-se possível recompor fatos do passado, sendo que estes aparecem, muitas vezes, como indícios de algum tipo de ação humana em certo período. Além disso, a apreciação documental possibilita a análise do desenvolvimento, do amadurecimento ou do progresso de indivíduos, grupos, conceitos, conhecimentos, comportamentos, mentalidades, práticas, entre outros (CELLARD, 2008).

\footnotetext{
Inacabamento na proporção em que, quanto mais excludentes forem os espaços sociais, mais necessidade ter-se-á de elaborar políticas de inclusão. Assim, como a exclusão vem sendo produzida constantemente, a inclusão possui esse caráter de inacabamento. Para Bueno (2008, p. 56), a bandeira da educação inclusiva é um horizonte sempre móvel, porque nunca alcançado: "A projeção que se faz do futuro é que continuarão a existir alunos excluídos, que deverão receber atenção especial para deixarem de sê-lo".
} 
Acrescentamos que o conceito de documento excede a concepção de textos escritos e/ou impressos. Os filmes, vídeos, slides, fotografias ou pôsteres também podem ser fontes documentais. Esses são empregados como subsídios, indícios e aclaramentos e, pelo seu teor, esclarecem certos temas e contribuem comprovando outros (FIGUEIREDO, 2007). Neste texto, contudo, analisamos somente documentos na forma escrita.

De acordo com Cellard (2008), a análise documental é precedida por uma análise preliminar, e deve respeitar cinco aspectos: o contexto, a autenticidade, a natureza, os autores e seus conceitos chave e a lógica interna do texto.

Portanto, neste trabalho, realizamos uma análise preliminar dos seguintes documentos:aprimeira versão da tradução da Declaração de Salamanca, realizada pela Coordenadoria Nacional para a Integração da Pessoa Portadora de Deficiência (CORDE), publicada em 1994 e reeditada em 19974, e a segunda versão da Declaração de Salamanca (1994), disponibilizada hoje em meio digital pelo site do Ministério da Educação do Brasil.

A análise preliminar confirmou a historicidade dos documentos supracitados pelo contexto histórico que os eliciava, ou seja, todos foram produzidos após os anos 1990, época que congregou o prenúncio de diversos movimentos em prol da educação inclusiva. Entretanto, a primeira versão encerrava um caráter semântico ampliado, no que tange o público da educação inclusiva, ou seja, a educação para todos e a escola comum como responsável maior por esta. De modo diferente, a versão da Declaração de Salamanca, disponível hoje na internet, alia a educação inclusiva à Educação Especial, isto é, a educação inclusiva é pontuada como "tarefa" quase exclusiva da e para a Educação Especial e seu público-alvo, atualmente designado na Política Nacional de Educação Especial na Perspectiva da Educação Inclusiva (BRASIL, 2008).

A apreciação da Declaração de Salamanca (1994) considerou também a sua autenticidade, pois trata-se de documento de natureza orientadora que foi elaborado por autoridades reconhecidas no campo educacional de diferentes países que têm em comum, como conceitos chave e lógica interna, orientações relacionadas à educação inclusiva.

\footnotetext{
A primeira versão da tradução da Declaração de Salamanca no Brasil, de 1994 e reeditada em 1997, não se encontra disponível na internet.
} 


\subsection{Antecedentes e gênese da Declaração de Salamanca}

O preceito "educação para todos" não é algo novo no cenário da humanidade, também não pode ser considerado um slogan provindo da Conferência Mundial sobre Educação para Todos realizada em Jomtien, em 1990, na Tailândia, que, como boa parte da bibliografia, dos periódicos e dos documentos afetos à área da Educação Especial, apresenta alusão primária aos movimentos de educação inclusiva.

Considerando isso, pode-se afirmar que este aforismo deriva de um embate entre a burguesia da Idade Medieval, que ambicionava por ser e fazer uso de direitos de cidadania universal, e os senhores feudais, que apreendiam a produção e que não queriam abrir mão dessa prerrogativa. Assim, haja vista o imperativo de exercer uma cidadania universal, a sociedade, que ingressava na era moderna, necessitava também que todos os cidadãos fossem escolarizados, provocando, assim, a ideia de educação universal, a "educação para todos" (TONINI, MARTINS, COSTAS, 2012).

Adicionando outros atores, deve-se citar os organismos internacionais, dentre eles, o Banco Mundial ${ }^{5}$, que vem patrocinando distintas reformas educacionais, que buscam abarcar todos os planos e modalidades de ensino, até mesmo no campo da Educação Especial. As intenções dessas reformas são a racionalidade financeira e a admissão do país, que a elas aderir, a um novo arranjo internacional do trabalho, no qual os países capitalistas periféricos terão como função o consumo da ciência e tecnologia, engendradas pelos países centrais, por exemplo, os Estados Unidos da América (TONINI, MARTINS, COSTAS, 2012).

Para Fonseca (2003), o Banco Mundial indica aos países chamados periféricos, como é o caso do Brasil, que estes precisam encaixar-se em certos critérios para pleitearem financiamentos:

[...] os critérios do Banco para a concessão de créditos sociais são estritamente atrelados à política de ajuste econômico. Assim, apesar da retórica de solidariedade para com os países pobres do planeta, as ações exercidas no quadro de financiamentos, constituem medidas meramente compensatórias ou de alívio para esse seguimento populacional. É preciso considerar que, embora a retórica seja continuamente proclamada na mídia, a verdadeira ideologia dos

O Banco Mundial nasce junto com o Fundo Monetário Internacional (FMI) no ano de 1944, nos Estados Unidos da América (EUA). 
acordos é ocultada do público em geral. [...] Para a concessão de créditos, o Banco Mundial definiu um conjunto de políticas, nas quais duas tendências são perceptíveis: a primeira é a vinculação dos objetivos educacionais à política de ajuste econômico do Banco; neste sentido, a oferta educacional deve ser seletiva, de forma que diminua os encargos financeiros dos estados. Por essa razão, o ensino fundamental (quatro primeiras séries) seria universalizado sob a responsabilidade do governo. À medida que ascende na escala educacional, a oferta de ensino deve ser repassada ao setor privado (2003, p. 18).

Nesse horizonte, o ideário de uma "educação para todos" e suas implicações para garantir o acesso a direitos e a bens sociais deve ser avaliado cuidadosamente, pois, sob a camuflagem de assegurar direitos universais, podem esconder-se ações ainda mais excludentes sob a égide da globalização. E, ainda, pode-se afirmar que as orientações do Banco Mundial vêm acarretando significativas influências em todos os níveis e modalidades de ensino, pautando-se pela relação custo-benefício, ou seja, no caso da Educação Especial, também é imprescindível que se reduzam os custos tanto em termos de recursos ${ }^{6}$ quanto em temos de formação de professores $^{7}$ (TONINI, MARTINS, COSTAS, 2012).

Garcia (2004, p. 12) já chamava atenção para os discursos produzidos sobre a "educação para todos" presentes nos documentos da UNESCO - Organização das Nações Unidas para a Educação, a Ciência e a Cultura (1990, 1994), os quais dispensaram tópicos importantes, tais como "as relações de desigualdade nas quais os países produzem e consomem, a exemplo das condições de restrições econômicas, barreiras comerciais, a divisão internacional do trabalho, entre outros elementos".

Desse modo, resolver as questões estruturais como as nomeadas por Garcia (2004) torna-se uma prerrogativa para propor a consolidação de políticas públicas que têm hoje, na Educação Especial, sob a perspectiva de educação inclusiva, sua manifestação.

Como forma de ampliar a discussão iniciada na Conferência Mundial sobre Educação Para Todos (1990) e a ideia de "educação para todos", realizou-se em Salamanca, Espanha, em 1994, a Conferência Mundial sobre Necessidades Educativas Especiais, onde foi elaborada a "Declaração de Salamanca e Linha de Ação Sobre Necessidades Educativas Especiais", que indica a difusão dos

\footnotetext{
6 Devemos compreender que uma "sala de recursos multifuncionais" é consideravelmente menos onerosa financeiramente que uma Classe Especial ou uma Escola Especial.

7 No Brasil, houve uma proliferação de cursos de aperfeiçoamento/extensão a distância (com menor investimento governamental) visando à formação para a Educação Especial.
} 
preceitos neoliberais, sob a forma de políticas públicas. A Declaração de Salamanca (1994) oferece um ordenamento de ações que preconizam os encaminhamentos educativos com ênfase na educação inclusiva.

A Declaração de Salamanca (1994) traz a educação inclusiva como a possibilidade de "reforçar" a ideia de "educação para todos", como se, até então, alunos com deficiência e/ou com outras necessidades educacionais especiais não frequentassem a escola. No entender de Bueno (2006), o texto parece desconsiderar que, antes da década de 1990, esses alunos já estavam presentes nas instituições de ensino, principalmente privadas.

Assim, a Declaração de Salamanca (1994) assume que "[...] as políticas educacionais de todo o mundo fracassaram no sentido de estender a todas as suas crianças a educação obrigatória e de que é preciso modificar tanto as políticas quanto as práticas escolares sedimentadas na perspectiva da homogeneidade do alunado" (BUENO, 2006, p. 16).

A primeira versão da tradução da Declaração de Salamanca é disponibilizada no Brasil em 1994 e reeditada em 1997, período no qual o contexto político do país caracterizava-se como democrático, em que grupos sociais começam a ter força. Com isso, na Educação Especial, temos a disseminação do pensar sobre a integração da pessoa com deficiência na escola comum, normatizada pela Política Nacional de Educação Especial vigente na época (BRASIL, 1994). Já a versão da Declaração de Salamanca disponível hoje no website do Ministério da Educação está envolta em um cenário político que aloca, na educação, a responsabilidade pela inclusão social e, dessa maneira, pode-se observar massivos investimentos ${ }^{8}$ na Educação Profissional e Tecnológica e no Ensino Superior, realizados com slogan de garantia de educação para todos, a qual possibilitará ao cidadão a inserção no mercado de trabalho e nas condições de consumo. Nessa lógica, no campo educacional, a educação inclusiva ganha força focada no âmbito da Educação Especial como sua promotora e responsável na escola.

Desse ponto de vista, podemos afirmar que a Educação Especial incorporou o formato de educação inclusiva por meio de uma nova política (BRASIL, 2008), política que a orienta, mas não abarca a complexidade conjuntural de um país de tantas desigualdades sociais e econômicas como o Brasil e o que concebe a relação entre as redes de ensino, seus professores e o alunado que dela fazem parte (TONINI, MARTINS, COSTAS, 2012).

\footnotetext{
8 A criação dos Institutos Federais, em 2008, e o aumento de cursos a distância são algumas ações decorrentes desse investimento, bem como os vários programas de incentivo aos estudantes desses níveis de ensino, destacando-se o Programa Nacional de Acesso ao Ensino Técnico e Emprego (Pronatec) e o Programa Institucional de Bolsas de Iniciação à Docência (Pibid).
} 


\subsection{Educação inclusiva e Educação Especial: algumas aproximações a partir da Declaração de Salamanca}

Compreendemos a Educação Especial enquanto área de conhecimento e modalidade de ensino que não se restringe aos processos de inclusão escolar do seu público na escola comum. Estudos de Bueno (2008) chamam nossa atenção para o fato da inclusão no espaço educacional estar sendo considerada, quase exclusivamente, um sinônimo de inclusão de alunos concebidos da Educação Especial, como se fossem apenas esses os excluídos do e no espaço de escolarização formal. Surge, desse modo, a necessidade de demarcar que o público da educação inclusiva não é o mesmo que o da Educação Especial, e que Educação Especial não é sinônimo de educação inclusiva (MICHELS; GARCIA, 2014).

Carvalho (2006) também se ocupou da discussão, afirmando que, normalmente, se identificam como sujeitos da educação inclusiva os alunos historicamente associados ao público da Educação Especial, e justifica que isso acontece porque a inclusão vem sendo discutida, ao longo do tempo, principalmente em fóruns da Educação Especial, entretanto, salienta:

[...] a distância entre o concebido e o realizado pode ser explicado pelo próprio entendimento que se tem de inclusão. $O$ fato de estar sendo discutida, predominantemente, em fóruns de Educação Especial, acarreta a falsa ideia de que a proposta é, apenas, para aqueles que têm sido considerados como o seu alunado (CARVALHO, 2006, p. 26, grifo nosso).

A maioria das pessoas, quando ouvem falar sobre a educação inclusiva ou quando são questionadas sobre o assunto, estabelece, quase de forma automática, uma relação com as pessoas com deficiência. Assim, a relação entre educação inclusiva e deficiência, de certa maneira, transformou-se em senso comum.

Contudo, Carvalho (2011, informação verbal) ${ }^{9}$ alerta que se pode "olhar" a inclusão sob dois vieses: um diz respeito aos sujeitos; o outro refere-se aos lócus onde o processo de inclusão acontece e/ou deve acontecer. Dessa maneira, pode-se tratar de inclusão de diferentes pessoas e em espaços sociais diversos, como inclusão de diversas pessoas, por exemplo, deficientes, quilombolas, indígenas, camponeses, etc., em políticas públicas de saúde, habitação, educação, entre outras.

Destarte, é importante pontuar que, embora a expressão educação inclusiva tenha sido interpretada no Brasil com mais ênfase na sua relação com a Educação

9 Este e outros aspectos foram esclarecidos pela autora, em diálogo mantido por telefone em 15/06/2011. 
Especial e com o seu alunado, ela é muito mais abrangente, e abarca diversos grupos (sujeitos) - afro-brasileiros, camponeses, surdos, quilombolas, deficientes, indígenas, anões, doentes crônicos, menores abandonados, órfãos, ciganos, entre tantos outros - que estão/estiveram fora da escola ou que não tiveram/têm suas necessidades educacionais atendidas pela escola.

Novamente, Bueno $(2006,2008)$ alerta para a razão de termos no Brasil a visão limitada acerca da educação inclusiva e de seus beneficiários. $\mathrm{O}$ autor relata que apenas a primeira versão da tradução da Declaração de Salamanca, realizada pela Coordenadoria Nacional para a Integração da Pessoa Portadora de Deficiência (CORDE), publicada em 1994 e reeditada em 1997, foi fiel ao texto original, as versões seguintes tiveram mudanças significativas. Uma dessas alterações foi a substituição, em todo o texto, dos termos integração/escolarização integradora pelos termos inclusão/escolarização inclusiva.

Outra diferença, no mínimo muito inquietante, foi a inserção da expressão Educação Especial que não constava na versão original da Declaração. Na tradução de 1994, encontra-se a seguinte redação:

A presente Linha de Ação sobre Necessidades Educativas Especiais foi aprovada pela Conferência Mundial sobre Necessidades Educativas Especiais [...]. Seu objetivo é definir a política e inspirar as ações dos governos, de organizações internacionais e nacionais de ajuda, de organizações não-governamentais e de outros organismos na aplicação da Declaração de Salamanca, de princípios, política e prática para as necessidades educativas especiais (BRASIL, 1997, p.17, grifo do autor).

Já a redação da versão disponível, atualmente no website do Ministério da Educação, é outra:

Esta Estrutura de Ação em Educação Especial foi adotada pela Conferência Mundial de Educação Especial [...]. Seu objetivo é informar sobre políticas e guias ações governamentais, de organizações internacionais ou agências nacionais de auxílio, organizações não-governamentais e outras instituições na implementação da Declaração de Salamanca sobre princípios, Política e prática em Educação Especial (p. 3, grifo nosso). 
$\mathrm{Na}$ última versão, encontramos trinta e cinco $^{10}$ vezes a expressão "Educação Especial" que, na maioria dos casos, foi inserida onde, originalmente, estava a expressão "necessidades educativas especiais". Tal alteração acabou por induzir a compreensão e interpretação de que os alunos com necessidades educativas especiais ${ }^{11}$ são aqueles tradicionalmente identificados como alunos da Educação Especial, quando, na verdade, a Declaração de Salamanca é bem mais ampla ao considerar como alunos e alunas com necessidades educativas especiais:

[...] crianças com deficiências e crianças bem-dotadas; crianças que vivem nas ruas e que trabalham; crianças de populações distantes ou nômades; crianças de minorias linguísticas, étnicas ou culturais e crianças de outros grupos ou zonas desfavorecidos e marginalizados. [...] No contexto desta Linha de ação, a expressão 'necessidades educativas especiais' refere-se a todas as crianças e jovens cujas necessidades decorrem de sua capacidade e ou de suas dificuldades de aprendizagem. Muitas crianças experimentam dificuldades de aprendizagem e têm, portanto, necessidades educativas especiais em algum momento de sua escolarização (BRASIL, 1997, p. 17-18, grifo nosso).

Nesse sentido, Bueno afirma:

Isto é, as crianças deficientes são apenas uma, entre tantas outras, das expressões concretas das chamadas necessidades educacionais especiais. [...] Em nenhum momento aparece no texto original da Declaração o termo 'Educação Especial' como responsável pelas políticas de integração/inclusão escolar. Com isso fica claro que o termo 'necessidades educativas especiais' abrange, com certeza, a população deficiente, mas não se restringe somente a ela (2008, p. 50).

Devido à inserção da expressão "Educação Especial" no texto da Declaração de Salamanca, as crianças com deficiências passaram a ser consideradas com necessidades educativas especiais, do mesmo modo, muitas crianças com necessidades educativas especiais tornaram-se público-alvo das políticas de Educação Especial, mesmo não tendo uma deficiência identificada. A partir dessas interpretações e mudanças na redação da tradução disponíveis hoje, ampliou-se o público-alvo da Educação Especial e, para Bueno (2008), as políticas de educação inclusiva, no Brasil, ficaram restritas ao âmbito da Educação Especial.

\footnotetext{
${ }^{10}$ Coincidência ou não, esse também foi o número de vezes que encontramos a palavra "inclusiva" na versão atual.

11 Usamos a expressão "necessidades educativas especiais" por ser a expressão adotada na primeira versão da Declaração de Salamanca publicada no Brasil.
} 
Ainda no que se refere a esse aspecto, Carvalho (2010, p. 38) complementa pontuando que, após a promulgação da Lei de Diretrizes e Bases da Educação Nacional n ${ }^{\circ} 9.394$ de 1996, a expressão necessidades especiais, expressa no Capítulo V,

[...] tornou-se mais abrangente, aplicando-se não só aos alunos com deficiências, como a todos aqueles 'excluídos' por diversas razões que os levam a ter necessidades especiais [...]. Em decorrência, também se ampliou o público-alvo da educação especial.

Dessa forma, a autora ressalta os perigos da ampla utilização das expressões necessidades especiais e necessidades educacionais especiais por profissionais da Educação Especial, afirmando que:

Como consequência dessa associação, todos os que se desviam dos padrões 'normais' entram para a categoria de alunos com necessidades educacionais especiais, percebidos como portadores de deficiência até que lhes seja aplicada uma outra 'etiqueta'. [...] a imprecisão e abrangência da expressão [...] tem expandido o número de alunos que se encaixam na categoria de necessidades educacionais especiais, passando a condição de deficientes, circunstancialmente produzidos (CARVALHO, 2010, p. 39 e 49).

Verificamos, ainda, que a Resolução $\mathrm{n}^{\circ} 02$ de 2001, que instituiu as Diretrizes Nacionais para a Educação Especial na Educação Básica, prevê que "a presente Resolução institui as Diretrizes Nacionais para a educação de alunos que apresentem necessidades educacionais especiais, na Educação Básica, em todas as suas etapas e modalidades" (BRASIL, 2001, grifo nosso). Com isso, o conceito de necessidades educacionais especiais foi se restringindo aos alunos atendidos pela Educação Especial.

O documento em questão considera como

[...] educandos com necessidades educacionais especiais os que, durante o processo educacional, apresentarem:

I - dificuldades acentuadas de aprendizagem ou limitação no processo de desenvolvimento que dificultem o acompanhamento das atividades curriculares, compreendidas em dois grupos:

a) aquelas não vinculadas a uma causa orgânica específica; 
b) aquelas relacionadas a condições, disfunções, limitações ou deficiências;

II - dificuldades de comunicação e sinalização diferenciadas dos demais alunos, demandando a utilização de linguagens e códigos aplicáveis;

III -altas habilidades/superdotação, grande facilidade de aprendizagem que os leve a dominar rapidamente conceitos, procedimentos e atitudes.

No Brasil, de certa forma, incluíram-se, no rol de alunos atendidos pela Educação Especial, todos os alunos com necessidades educativas especiais quando a "Conferência Mundial sobre Necessidades Educativas Especiais" transforma-se em "Conferência Mundial de Educação Especial", título do documento nas versões disponíveis atualmente na internet. Por outro lado, quando foram elaboradas as políticas de Educação Especial, apenas os alunos já considerados como público da Educação Especial foram considerados como pertencentes à categoria "necessidades educacionais especiais", visto que a Resolução $\mathrm{n}^{\circ} 02$ de 2001 instituiu as Diretrizes Nacionais para a Educação Especial na Educação Básica.

Mesmo que as "crianças que vivem nas ruas e que trabalham; crianças de populações distantes ou nômades; crianças de minorias linguísticas, étnicas ou culturais e crianças de outros grupos ou zonas desfavorecidos e marginalizados" (BRASIL, 1997, p. 18) possam ser consideradas com dificuldades de aprendizagem não vinculadas a uma causa orgânica específica, a Resolução ${ }^{\circ} 02$ de 2001 não faz referência direta a elas.

Assim sendo, na elaboração das políticas públicas para Educação Especial no Brasil, inclui-se e exclui-se e, conforme se inclui, exclui-se duplamente. Muitos dos alunos com necessidades educativas especiais, incluídos/elencados na Declaração de Salamanca, não foram contemplados pelas políticas de Educação Especial, ou seja, foram incluídos em um primeiro momento e excluídos posteriormente, contudo, ao serem incluídos/apropriados como sujeitos das ações da Educação Especial na segunda versão da Declaração de Salamanca, possivelmente, deixaram de ser sujeitos de outras ações, sendo, assim, excluídos duplamente.

Igualmente, consideramos que se excluiu ainda mais com a publicação da Política Nacional de Educação Especial na Perspectiva da Educação Inclusiva (BRASIL, 2008), que define como objetivo

\section{[...] assegurar a inclusão escolar de alunos com deficiência, transtornos globais do desenvolvimento e altas habilidades/superdotação, orientando os sistemas de ensino para garantir: acesso ao ensino regular,}


com participação, aprendizagem e continuidade nos níveis mais elevados do ensino; transversalidade da modalidade de Educação Especial desde a educação infantil até a educação superior; oferta do atendimento educacional especializado [...] (BRASIL, 2008, p. 14, grifo nosso).

Nestes casos e outros, que implicam em transtornos funcionais específicos, a Educação Especial atua de forma articulada com o ensino comum, orientando para o atendimento às necessidades educacionais especiais desses alunos [...] (BRASIL, 2008, p. 15, grifo nosso).

É possível compreender que a expressão necessidades educacionais especiais foi utilizada de forma diferente daquela adotada na Declaração de Salamanca e na Resolução $n^{\circ} 02$ de 2001, visto que os alunos público-alvo da Educação Especial deverão ter as suas "necessidades educacionais especiais" atendidas, assim os alunos com "necessidades educacionais especiais" não são mais o público-alvo da Educação Especial (BRASIL, 2001).

Desse modo, entendemos que as garantias da Política Nacional de 2008 se referem aos alunos com deficiência, transtornos globais do desenvolvimento e altas habilidades/superdotação, porém, ao fazer referência a "e outros, que implicam em transtornos funcionais específicos", ela não se limita apenas aos primeiros, embora a garantia de atendimento educacional especializado seja apenas para eles.

A Resolução n 02 de 2001 diminui/limita o número de "necessidades educacionais especiais" e, por último, a atual Política Nacional de Educação Especial (BRASIL, 2008) nem se refere à expressão "necessidades educativas especiais" ou "necessidades educacionais especiais", quando nomeia o seu público-alvo.

Decorrem dessas análises alguns questionamentos: será que a atual Política ${ }^{12}$ não é uma forma de reconhecer que a Educação Especial não abrangeu todas aquelas crianças com alguma dificuldade de aprendizagem que poderiam ser também "crianças que vivem nas ruas e que trabalham; crianças de populações distantes ou nômades; crianças das minorias linguísticas, étnicas ou culturais e crianças de outros grupos ou zonas desfavorecidos ou marginalizados" (BRASIL, 1997, p. 17-18)? O que aconteceu com as crianças em questão a partir de 2008 ?

\footnotetext{
12 Outro aspecto polêmico da Política refere-se à definição de pessoa com deficiência, que insere, novamente, a pessoa surda na condição de deficiente. Ressaltamos que, pela Resolução CNE/CEB n 2 de 2001, o surdo não era mais concebido como deficiente, ou deficiente da áudio comunicação, mas considerado uma pessoa com dificuldade de comunicação e com sinalização diferenciada. Podemos inferir que a atual Política regrediu, não atentando para as investigações dos estudiosos da área e a militância da comunidade surda que vêm utilizando expressões como: sujeito da diferença linguística e cultural.
} 
Elas deixaram de existir? A escola está conseguindo ensiná-las? O que vai acontecer com elas?

São evidentes as consequências deletérias das alterações na Declaração de Salamanca. Suas influências nas proposições políticas também podem ter interferido nos cursos de formação de professores e nas pesquisas acadêmicas, na medida em que as políticas educacionais servem como referências para eles (COSTAS, 2008).

Ainda, podemos verificar que as pesquisas da Educação Especial sofrem/sofreram influências das modificações na versão da Declaração de Salamanca. A primeira é que a versão hoje disponível pode produzir uma interpretação equivocada sobre a educação inclusiva - que não é sinônimo de Educação Especial - pois nem todos os pesquisadores sabem da existência das duas versões diferentes da Declaração e têm acesso a elas, visto que a primeira versão não se encontra disponível no site do Ministério de Educação ou outro. Um segundo aspecto em que a Declaração de Salamanca interfere é na elaboração das políticas de educação inclusiva e Educação Especial, sendo que estas, muitas vezes, são tratadas e mostradas como interdependentes, como se não existisse Educação Especial fora da perspectiva da educação inclusiva. Ainda, há que se considerar as consequências para o meio educacional que advêm dessas traduções e interpretações, visto que elas passam a ser basilares para outras investigações, outras políticas e para as ações no contexto escolar (BREITENBACH, 2012).

Bueno $(2006,2008)$ traz evidências nesse sentido, pois, ao analisar dissertações e teses produzidas entre os anos de 1997 e 2003, observou que a inclusão é tratada como uma política restrita àqueles sujeitos que já vinham sendo atendidos pela Educação Especial, visto que apenas 15 dos 127 trabalhos analisados voltaram-se para outros sujeitos, embora 39 destes 127 trabalhos tenham usado a expressão "necessidades educacionais especiais" para fazer referência aos seus sujeitos de pesquisa.

Nessa direção, corroboram Michels e Garcia (2014, p.158), ao observarem que:

Mais recentemente, notamos o uso do adjetivo 'inclusivo' como estratégia para atribuir novos significados ao termo sistema educacional. Observamos que um dos objetivos anunciados no âmbito das políticas de educação inclusiva é transformar o sistema educacional em 'sistema educacional inclusivo'. 
A partir disso, questionamos sobre as nomeadas escolas inclusivas, pois, se a educação inclusiva não é restrita à Educação Especial, será que seria suficiente termos nas escolas os alunos desta para que as escolas sejam adjetivadas como inclusivas? E há, de fato, um "sistema educacional inclusivo"?

No âmbito do Rio Grande do Sul, estado do qual somos provenientes, o Parecer $n^{\circ}$ 441/2002 (Rio Grande do Sul, 2002), em concordância com a Declaração de Salamanca (BRASIL, 1997), apresenta que a escola, pautada em uma educação inclusiva, deve compreender um caráter de escola inclusiva, não somente por receber alunos nomeados nessa Declaração com "necessidades educativas especiais", ou por receber os alunos público-alvo da Educação Especial, mas por ser uma instituição que se mostra e está disposta a criar condições pedagógicas, didáticas, ambientais e curriculares para acolher e acompanhar todo e qualquer estudante em sua escolarização.

César (2003), Sanches e Teodoro (2007) baseados em Ainscow (1995), Rodrigues (2001) e Correia (2001) afirmam que a escola que orienta suas ações buscando efetivar a educação inclusiva deve acolher e acompanhar todos os sujeitos, independentemente de sexo, cor, religião, origem, condição física, social ou intelectual. A partir disso,

[...] escola inclusiva é uma escola onde se celebra a diversidade, encarando-a como uma riqueza e não como algo a evitar, em que as complementaridades das características de cada um permitem avançar, em vez de serem vistas como ameaçadoras, como um perigo que põe em risco a nossa própria integridade, apenas porque ela é culturalmente diversa da do outro, que temos como parceiro social (CÉSAR, 2003, p.119).

Nessa perspectiva, entendemos que a educação inclusiva não se restringe a proporcionar acesso e qualidade de ensino formal a pessoas tidas como público-alvo da Educação Especial, como muitos profissionais da educação pensam. Compreendemos que a educação inclusiva pressupõe promover uma equidade educacional, por meio da garantia de acesso e qualidade na educação de todas as pessoas.

Desse modo, a educação inclusiva, proposta principalmente pela Declaração de Salamanca, em sua primeira tradução, implica na garantia de acesso, permanência e qualidade no ensino para as pessoas que, historicamente, ficaram fora da escola ou nela não aprenderam. 


\section{Considerações finais}

A partir do exposto, torna-se difícil compreender por que a Declaração de Salamanca foi reeditada com as alterações apresentadas. Ressaltamos particularmente a modificação do nome do evento de "Conferência Mundial sobre Necessidades Educativas Especiais" (na versão original da Declaração de Salamanca, publicada pela CORDE em 1994) para "Conferência Mundial de Educação Especial", expresso nas versões disponíveis atualmente desse documento. Pode-se atribuir isso ao fato da educação inclusiva ser um tema discutido ao longo do tempo, principalmente, em fóruns da Educação Especial (CARVALHO, 2006).

É possível observar que as políticas públicas para a educação inclusiva e para a Educação Especial foram/estão sendo propostas tendo por base as modificações e interpretações dessa Declaração. Além disso, verificamos que o cenário instaurado por essas alterações vincula a educação inclusiva basicamente à Educação Especial, como se aquela fosse dirigida exclusivamente a esta.

Dessa forma, as alterações aparentemente despretensiosas na Declaração de Salamanca e a miscelânea de conceitos e definições sobre as pessoas denominadas público-alvo da educação inclusiva e da Educação Especial podem ter causado muitas confusões conceituais e, certamente, conduzido o rumo da história das políticas e pesquisas sobre educação inclusiva e Educação Especial no Brasil.

Assim, ao finalizar este texto, consideramos que a Declaração de Salamanca poderia ter sido o marco das políticas de Educação Especial, mesmo sem as alterações nela realizadas, que parecem "monopolizar" a educação inclusiva como sendo uma tarefa exclusivamente da Educação Especial. Sem a ocorrência de tais mudanças neste documento, talvez, poderíamos ter hoje outra interpretação sobre a educação inclusiva, menos confusões conceituais e mais ações educacionais para todos os alunos. 


\section{Inclusive education: implications of the translations and interpretations of the Salamanca Statement in Brazil}

\section{Abstract}

The changes in the current version of the Salamanca Statement, and its influence in the elaboration of legal documents, confirm that inclusive education and Special Education have been considered synonyms in our country. Thus, this article problematizes the concept of inclusive education disseminated in public policies and in the Brazilian school context from the first translation of the Salamanca Statement, available in 1994 and re-edited in 1997; and from the second translation of this document, that is currently available at the website of the Ministry of Education. The methodology involved a documental research and analysis that sought to determine and to analyze how the alterations in the Salamanca Statement, as published and conveyed in Brazil, set the inclusive education as a task of Special Education, provoking a miscellany of concepts, definitions and interpretations relating these two expressions. It was possible to observe that the public policies for inclusive education and Special Education were/are being proposed having as basis the modifications and the interpretations of this Statement. The alterations, apparently unpretentious, in the Salamanca Statement and the variety of concepts and definitions about the people who are target of inclusive education and of Special Education could have caused a conceptual confusion and, certainly, defined the course of the history of the policies and research related to these themes in Brazil.

Keywords: Inclusive education. Special Education. Declaration of Salamanca.

\section{Educación inclusiva: las implicaciones de las traduciones y de las interpretaciones de la Declaración de Salamanca en Brasil}

\section{Resumen}

Los cambios en la actual versión de la Declaración de Salamanca, y su influencia en la elaboración de los documentos legales, confirman que la educación inclusiva y la Educación Especial han sido consideradas sinónimos en nuestro país. Así, ese artículo cuestiona el concepto de educación inclusiva difundido en las politicas públicas y en el contexto escolar brasilero a partir de la primera traducción de la Declaración de Salamanca, disponible en 1994 y revisada en 1997; también de la segunda traducción, que hoy está disponible en medio digital en el sitio web del Ministerio de la Educación. La opción metodológica incluyó una investigación y un análisis documental. Se buscó constatar y analizar cómo las alteraciones en la Declaración de Salamanca, hoy divulgada en Brasil, ponen la educación inclusiva como tarea de la Educación Especial, lo que provocó una variedad de conceptos y definiciones relacionados con estas dos expresiones. Fue posible observar que las políticas públicas para la educación inclusiva y para la Educación Especial fueron/están siendo propuestas considerando las modificaciones y las 
interpretaciones de esta Declaración. Las alteraciones, aparentemente sin pretensiones en la Declaración de Salamanca, y la variedad de conceptos y definiciones sobre las personas que la educación inclusiva y la Educación Especial pretenden alcanzar, pueden haber causado confusiones conceptuales, y posiblemente, conducido el curso de la historia de las políticas e investigaciones sobre la educación inclusiva y la Educación Especial en el Brasil.

Palabras clave: Educación inclusiva. Educación Especial. Declaración de Salamanca. 


\section{Referências}

AINSCOW, M. Education for all: making it happen. In: CONGRESSO INTERNACIONAL DE EDUCAÇÃO ESPECIAL, 1995, Brimingham. Comunicação...1995, p. 147-155. Disponível em: <http://onlinelibrary.wiley.com/ doi/10.1111/j.1467-9604.1995.tb00031.x/abstract>. Acesso em: 23 jun 2015.

BRASIL. Declaração de Salamanca e linha de ação sobre necessidades educativas especiais. 2. ed. Brasília, DF: Corde, 1997.

. Conselho Nacional de Educação. Câmara de Educação Básica.

Resolução n², de 11 de setembro de 2001. Institui Diretrizes Nacionais para a Educação Especial na Educação Básica. In: DIREITO a educação: necessidades educacionais especiais: subsídios para a atuação do ministério público Brasileiro. Brasília, DF, 2001. Disponível em: $<$ http://www.dominiopublico.gov. br/download/texto/me002217.pdf>. Acesso em: 23 jun. 2015.

. Lei no 9.394, de 20 de dezembro de 1996. Estabelece as Diretrizes e Bases da Educação Nacional. Diário oficial [da] República Federativa do Brasil, Brasília, DF, 23 dez. 1996. Disponível em: <http://www.planalto.gov. br/ccivil_03/leis/19394.htm>. Acesso em: 23 jun. 2015.

. Ministério da Educação. Secretaria de Educação Especial. Política Nacional de Educação Especial. Brasília, DF: MEC/SEESP, 1994.

. Ministério da Educação. Secretaria de Educação Especial. Política Nacional de Educação Especial na Perspectiva da Educação Inclusiva. Brasília, DF, 2008. Disponível em: <http://portal.mec.gov.br/arquivos/pdf/ politicaeducespecial.pdf $>$. Acesso em: 12 maio 2015.

BREITENBACH, F. V. Propostas de Educação Inclusiva dos Institutos Federais do Estado do Rio Grande do Sul: alguns apontamentos. 2012. 137 f. Dissertação (Mestrado)-Programa de Pós-graduação em Educação. Universidade Federal de Santa Maria, Santa Maria, 2012.

BUENO, J. G. S. Inclusão/exclusão escolar e desigualdades sociais. 2006. Projeto de pesquisa. Disponível em: <http://www4.pucsp.br/pos/ehps/ downloads/inclusao_exclusao_escolar.pdf $>$. Acesso em: 03 jun. 2015.

. As políticas de inclusão escolar: uma prerrogativa da Educação Especial? In: BUENO, J. G. S.; MENDES, G. M. L.; SANTOS, R. A. (Org.). Deficiência e escolarização: novas perspectivas de análise. Araraquara: Junqueira e Marin; Brasília, DF, CAPES, 2008. p. 43-63. 
CARVALHO, R. E. Educação inclusiva: com os pingos nos "is". 4. ed. Porto Alegre: Mediação, 2006.

. Removendo as barreiras para a aprendizagem: educação inclusiva.

9. ed. Porto Alegre: Mediação, 2010.

CELLARD, A. A análise documental. In: POUPART, J. et al. A pesquisa qualitativa: enfoques epistemológicos e metodológicos. Petrópolis: Vozes, 2008. p. 295-316.

CÉSAR, M. A escola inclusiva enquanto espaço-tempo de diálogo de todos para todos. In: RODRIGUES, D. Perspectivas sobre a inclusão: da educação à sociedade. Porto: Porto Editora, 2003. p. 117-149.

CORREIA, L. Educação inclusiva ou educação apropriada? In: RODRIGUES, D. (Org.). Educação e diferença: valores e práticas para uma escola inclusiva. Porto: Porto Editora, 2001. p. 123-142.

COSTAS, F. A. T. Educação inclusiva: reflexões acerca do processo e da nova política nacional. Revista Educação Cidadã, Santa Maria, v. 1, n. 1, p. 16, 2008.

FIGUEIREDO, N. M. A. Método e metodologia na pesquisa cientifica. 2. ed. São Caetano do Sul: Yendis Editora, 2007.

FONSECA, M. A gestão da educação básica na ótica da cooperação internacional: um salto para o futuro? In: VEIGA, I. P. A; FONSECA, M. As dimensões do projeto político-pedagógico. Campinas: Papirus, 2003. p. 13-41.

GARCIA, R. M. C. Políticas públicas de inclusão: uma análise no campo da educação especial brasileira. 2004. 216 f. Tese (Doutorado em Educação) - Universidade Federal de Santa Catarina, Florianópolis, 2004.

LÜDKE, M.; ANDRÉ, M. E. D. A. Pesquisa em educação: abordagens qualitativas. São Paulo: EPU, 1986.

MICHELS, M. H.; GARCIA, R. M. C. Sistema educacional inclusivo: conceito e implicações na política educacional brasileira. Cadernos Cedes, Campinas, v. 34, n. 93, p. 157-173, 2014. Disponível em: <http://www.cedes.unicamp.br>. Acesso em: 10 fev. 2015. doi:10.1590/S0101-32622014000200002

RIO GRANDE DO SUL (Estado). Ministério Público. Parecer nº 441/2002. Parâmetros para a oferta da Educação Especial no Sistema Estadual de Ensino. 
Porto Alegre, 2002. Disponível em: <http://www.mp.rs.gov.br/infancia/ legislacao/id3162.htm?impressao=1>. Acesso em: 23 jun. 2015.

RODRIGUES, D. (Org.). Educação e diferença:valores e práticas para uma escola inclusiva. Porto: Porto Editora, 2001.

SANCHES, I.; TEODORO, A. Procurando indicadores de educação inclusiva: as práticas dos professores do apoio educativo. Revista Portuguesa de Educação, Braga, v. 20, n. 2, p. 105-149, 2007.

TONINI, A.; MARTINS, A. P. L.; COSTAS, F. A. T. Dificuldades de aprendizagem específicas: uma análise entre Brasil e Portugal. Revista de Educação Especial e Reabilitação, Lisboa, v. 18, p. 9-43, 2012.

\section{Informações das autoras}

Fabiane Vanessa Breitenbach: Doutoranda do Programa de Pós-Graduação em Educação, Universidade Federal de Santa Maria - UFSM. Técnica em Assuntos Educacionais do Núcleo de Acessibilidade - UFSM. Professora externa do Curso de Graduação em Educação Especial - UFSM Contato: fabiane.breitenbach@gmail.com

Cláucia Honnef: Doutoranda do Programa de Pós-Graduação em Educação, Universidade Federal de Santa Maria - UFSM. Professora externa do curso de Graduação em Educação Especial - UFSM. Contato: profclaucia@gmail.com

Fabiane Adela Tonetto Costas: Doutoranda do Programa de Pós-Graduação em Educação, Universidade Federal de Santa Maria - UFSM. Professora da Unidade de Educação Infantil Ipê Amarelo. Professora externa do Curso de Graduação em Educação Especial - UFSM. Contato: profclaucia@gmail.com 